\title{
Facebook-Based Social Marketing to Reduce Smoking in Australia's First Nations Communities: An Analysis of Reach, Shares, and Likes
}

Marita Hefler ${ }^{1}$, BAsianStudies, GradDipIntSocDev, MPH, PhD; Vicki Kerrigan ${ }^{1}$, BA, MIntl\&ComnDev; Anne Grunseit $^{2}$, BA, PhD; Becky Freeman ${ }^{2}$, BSc, MSc, PhD; James Kite ${ }^{2}$, BA, MPH, PhD; David P Thomas ${ }^{1}$, MBBS, MMedSc, PhD, FAFPHM

\footnotetext{
${ }^{1}$ Menzies School of Health Research, Charles Darwin University, Casuarina, Australia

${ }^{2}$ Prevention Research Collaboration, Sydney School of Public Health, The University of Sydney, Sydney, Australia
}

\section{Corresponding Author:}

Marita Hefler, BAsianStudies, GradDipIntSocDev, MPH, PhD

Menzies School of Health Research

Charles Darwin University

PO Box 41096

Casuarina, 0810

Australia

Phone: 61889468517

Email: marita.hefler@menzies.edu.au

\section{Abstract}

Background: Facebook is widely used by Australia's First Nations people and has significant potential to promote health. However, evidence-based guidelines for its use in health promotion are lacking. Smoking prevalence among Australia's First Nations people is nearly 3 times higher than other Australians. Locally designed programs in Aboriginal Community Controlled Health Services (ACCHOs) to reduce smoking often use Facebook.

Objective: This study reports on an analysis of the reach and engagement of Facebook posts with smoking prevention and cessation messages posted by ACCHOs in the Northern Territory, Australia.

Methods: Each service posted tobacco control content at least weekly for approximately 6 months. Posts were coded for the following variables: service posted, tailored First Nations Australian content, local or nonlocally produced content, video or nonvideo, communication technique, and emotional appeal. The overall reach, shares, and reactions were calculated.

Results: Compared with posts developed by the health services, posts with content created by other sources had greater reach (adjusted incident rate ratio [IRR] 1.92, 95\% CI 1.03-3.59). Similarly, reactions to posts (IRR 1.89, 95\% CI 1.40-2.56) and shared posts (IRR 2.17, 95\% CI 1.31-3.61) with content created by other sources also had more reactions, after controlling for reach, as did posts with local First Nations content compared with posts with no First Nations content (IRR 1.71, 95\% CI 1.21-2.34).

Conclusions: Facebook posts with nonlocally produced content can be an important component of a social media campaign run by local health organizations. With the exception of nonlocally produced content, we did not find a definitive set of characteristics that were clearly associated with reach, shares, and reactions. Beyond reach, shares, and likes, further research is needed to understand the extent that social media content can influence health behavior.

(J Med Internet Res 2020;22(12):e16927) doi: 10.2196/16927

\section{KEYWORDS}

social media; tobacco; Australia; indigenous peoples; smoking; health promotion 


\section{Introduction}

\section{Social Media and Health}

Social media are an essential component of public health, as a tool for health communication, an avenue for consumers seeking information, and an environment that shapes health, analogous to the influence of the built environment [1]. Although social media have fundamentally altered health promotion [2], considerable uncertainty remains regarding how health services can use them effectively $[3,4]$. The rapid change in the social media landscape challenges the capacity of health promoters to develop a robust evidence base for what works; as a result, there are no clear guidelines for population-based social media strategies to promote health. Numerous reviews have concluded that social media have the potential to positively affect health but have found either mixed [5,6] or no definitive evidence [7-11] of their impact on health behavior, even as research in the field has significantly increased in recent years.

Consumer benefits of using social media for health information include social and emotional support and connectedness from peer-to-peer interactions [12-14]. Similarly, social media are an opportunity for health services to engage in building social capital within their communities [15] and a potentially cost-effective way to achieve significant reach for social marketing and health promotion [3]. Social media may also be effective for engaging specific groups who experience disadvantage and, therefore, contribute to reducing health inequity, although more research is needed [10].

Social marketing and mass media are an important and cost-effective strategy for reducing smoking [16-19]. Social media are an increasingly integral component of mass media strategies, and Australian research suggests that social media alone are more cost-effective than television advertising for tobacco control social marketing [20]. Social media also complement strategies such as smoking cessation services [21]. Facebook can also be effective for connecting with otherwise hard-to-reach smokers [22], including with people who are not social media users when people show content that appears on their Facebook feed to people who do not have an account [15].

Worldwide, Facebook is the largest social media platform, with nearly 2.8 billion active users [23]. In Australia, it is the most widely and frequently used platform, with 15 million active users (equivalent to $60 \%$ of the population) and $50 \%$ of the population using it daily [24]. Facebook is a comparatively inexpensive way for health services to communicate with the public [25], allowing for a spectrum of engagement from low to high [26]. Unlike many other platforms, Facebook is used by all ages, including older adults, for whom it can have both social and health benefits $[13,14,27]$. Studies examining the characteristics of posts that generate engagement have found diverse results; some have found videos to be effective [28], others have found photos to be effective [29], and some have identified that paid boosts and page promotions stimulate engagement $[26,30]$ and that the time of day or day of week and organic versus paid posts are also factors that determine both reach and engagement [30]. The Facebook algorithm appears to increasingly prioritize posts from personal contacts rather than unpaid posts from organizational or business pages [31]. In this context, health services need to understand how they can use Facebook to reach key target groups and track both reach and engagement.

\section{Social Media and Australia's First Nations People}

Although data are limited, social media-and specifically Facebook-use appears to be higher among Australia's First Nations people than other Australians [32-34]. Facebook has been found to be a supportive environment which is used by Australia's First Nations people to share health information $[35,36]$. The high use of social media by Australia's First Nations peoples is not limited to urban areas; particularly in remote communities, Australia's First Nations people are likely to be mobile only users in relation to communication, with social media access often occurring through shared devices [37].

Unsurprisingly, the lack of clear evidence about how to use social media effectively to improve health is reflected in reviews about how social media can be used to improve the health of Australia's First Nations people [36,38]. However, research is promising that social media can help with promoting healthy behaviors [39]. In Australia, the use of social media by First Nations people has some specific characteristics, including engagement between youth and older adults, which promotes intergenerational connection [33]. Social media is therefore an appropriate channel for communicating messages to Australia's First Nations people as part of social marketing and mass media campaigns.

\section{Australia's First Nations People and Smoking}

Nationally, smoking prevalence among Australia's First Nations people is nearly 3 times higher than that among non-Indigenous Australians [40]. To address this, the national Tackling Indigenous Smoking Program is funded by the Australian government till June 30, 2022. It is implemented through 37 Aboriginal Community Controlled Health Services (ACCHOs) to deliver locally designed programs to reduce smoking in their communities [41] and includes the use of mass media, both legacy (television, radio, and newspaper) and social media. These local health services therefore play an essential role in disseminating information to localize and make relevant key tobacco control messages and generate awareness of cessation support for smokers.

\section{Study Objective}

This study reports on an analysis of Facebook post reach and engagement with smoking prevention and cessation messages posted by ACCHOs in the Northern Territory, Australia.

A note regarding terminology: the original inhabitants of what is now known as Australia have diverse cultures, languages, and kinship structures. Throughout this paper, the term Australia's First Nations is used, unless referring specifically to service or program names that use Indigenous or Aboriginal in the title. 


\section{Methods}

\section{Setting}

In 2016, the Northern Territory had an estimated population of 245,048 people [42]. The Northern Territory has both the highest proportion of First Nations people (23.8\%) [42] and the highest smoking prevalence compared with any other Australian jurisdiction. Among people aged 18 years or older, the daily smoking prevalence in the Northern Territory in 2017 to 2018 was $19.6 \%$, compared with $13.8 \%$ of all Australians [43]. In 2014, the daily smoking prevalence among First Nations people in the Northern Territory was $45 \%$ [44].

This study was undertaken with 3 ACCHOs in the Northern Territory, located in a mix of urban and remote locations. It was designed to meet an identified need for services to have a better, context-specific understanding of what content works well with their communities. Implementation was participatory, flexible, and pragmatic, based on real-world circumstances for, and decision making by, each service (rather than imposing a set approach to selecting and posting content). All the services received funding from the Tackling Indigenous Smoking Program. The approach and factors explored in this study were based on guidance from the services that were partners in this project and feedback from other services that receive Tackling Indigenous Smoking Program funding. One participating service (hereafter referred to as service 3) had an organizational Facebook page before the commencement of the study; the other 2 started their Facebook pages during the study. Data were collected from the time of the first tobacco-related post during the study period. Each service posted a mix of tobacco control content, other health information, and general information during the study period. Data collected and analyzed for this study only included tobacco-related posts. One health service paid to boost the reach of 2 posts. With only 2 posts, it was not possible to assess the impact of these posts on reach.

One health service that started its Facebook page during the study had an in-house specialist communications manager who was responsible for coordinating and managing posts for this study, as part of managing social media communications for the service. The other 2 services received support and mentoring from VK (project manager with the research institute) throughout the study period, including technical assistance to develop content, support for crafting messages, and risk management for negative public comments. This technical support was part of the overall project design, as requested by the partner services. VK has 2 decades of experience as a journalist, including administration of local Facebook accounts for a national media outlet. The support provided by VK was part of capacity building and reciprocity, which was embedded in the project approach, in line with Australian national guidelines for ethical conduct in Aboriginal and Torres Strait
Islander health research [45]. The project was approved by the Northern Territory Department of Health and Menzies School of Health Research Human Research Ethics Committee and the Central Australian Human Research Ethics Committee, although ethics approval was not required for this component.

\section{Data Collection}

Facebook analytic data (available to page administrators) were collected for the duration of each health service's participation in the project. Data were collected 7 to 14 days after each post. The difference in time between posting and data collection is unlikely to have affected the overall reach, as most reach and interactions with Facebook posts are known to be achieved within 24 hours of posting [46]. The study period and timeframe were different for each service to take into account operational priorities, staff capacity, and holiday close down periods.

\section{Outcome Variables}

We collected the following outcome measures for each post:

- Overall reach: the total number of unique users exposed to the original post and shares, as defined by Facebook. Facebook insights do not provide a breakdown of exposure to the original post and shares.

- Total shares: includes shares of the original post and on-shares (shares of the shared post). This category also includes shares of posts that the health service posted on its own page and then shared to the page of another organization.

- Reactions to original post: all reactions (like, love, laugh, angry, sad, and wow) and comments on a post by the health service. Does not include shares of the post or reactions to on-shares.

- Reactions to shared posts: all reactions (like, love, laugh, angry, sad, and wow) and comments to posts from the health service that were shared by others.

Reactions to original posts and shared posts were analyzed separately to provide insight into differences in the magnitude of reactions to original posts compared with shared posts. Furthermore, it was not always possible to determine what was included in shared posts - for example, comments by the health services on the original post may not have been included or people may have added their own comments when sharing posts that were not visible to the research team.

\section{Independent Variables}

We adapted previous coding frames $[28,47]$ for post content to take into account the smaller volume of posts analyzed in this study and ensure that codes were locally relevant. Coding criteria were determined by agreement between 3 authors (VK, $\mathrm{MH}$, and DT), with potential discrepancies resolved at this stage. Codes were then assigned by 1 author (VK; Textbox 1), except for emotional appeal (see definition in Textbox 1). 
Textbox 1. Coding frame for post content (item and definition).

- Who posted: Health service 1,2 , or 3

- First Nations (Australia) tailoring:

- Non-First Nations: General tobacco control messages, whether Australian or international, not featuring any First Nations people, words or images

- First Nations Australia—general: Australian content, tailored to First Nations people, but not specific to the health service location. Includes content from locations in the Northern Territory, but outside the catchment area or footprint of the health service, and content developed by other services in the project

- First Nations Australia-local: Content which has features that are localized to health service area. Includes First Nations Australia general content with local branding features such as local health service logo or translated into language

- Content origin:

- Original: Content developed by the health service which posted the content

- Other sources: Content created by a source other than the health service, even if localized to the health service (eg, Australian Government Department of Health "Don't make smokes your story" campaign images translated into the local language and/or with a logo of a local health service added)

- Post type: Includes or does not include video

- Communication techniques:

- Other orgs tagged—no or yes

- Hashtags used-yes or no

- Emotional appeal: As this is influenced by cultural background, posts from each health service were coded by 2 community members living in the catchment area of each service. Coders were requested to code each post as negative, positive, or neutral. Coding was based on their perceptions of the post; the intended emotional appeal of the content was not known by the researchers or coders. If coders perceived the post as having no emotional elements or both positive and negative elements, they were asked to code it as neutral. Posts that were coded differently by each community member were combined with those that were coded as neutral by both. As no posts were coded as negative by the coders, 2 final categories were used for analysis: (1) positive and (2) neutral or disagreement (contested) between coders

First, we calculated the number of posts, shares, reactions, and median reach per post over the independent variables. Second, we conducted a series of (separate) bivariate negative binomial regressions (the data were overdispersed) for each outcome (reach, shares, reactions to original post, and reaction to shared posts) over each of the 6 explanatory variables, and then multivariate regressions including all of the explanatory variables. The reference category for health service was health service 1. For First Nations tailoring, it was non-First Nations content; for content origin, it was original content; for post type, it was nonvideo; and for whether other organizations were tagged or hashtags were used, the reference categories were not tagged and no hashtags, respectively, and neutral or mixed was the reference category for emotional appeal.

Estimated coefficients for multicategory variables (health service and First Nations tailoring) were tested jointly postestimation for statistical significance of the variable using Wald tests. The analyses were initially conducted without an offset and then controlling for users' exposure to the post by including reach as an offset variable to estimate engagement while accounting for the number of people to whom each post was delivered [48]. For the unadjusted analyses, the outcome (incident rate ratio [IRR]) indicates the multiplicative change in outcome compared with the reference category for that explanatory variable. For the adjusted analyses, the relationship between explanatory variables and engagement becomes the change in the outcome per person. The threshold for statistical significance was set at $P=.05$.

\section{Results}

Service 1 participated for 23 weeks from August 2017, service 2 for 19 weeks from July 2017 to March 2018, and service 3 for 19 weeks from May to December 2017. We coded 92 posts from the study period (Table 1). 
Table 1. Overall reach of each type of post (both of the original post and when shared).

\begin{tabular}{|c|c|c|c|c|c|c|c|c|}
\hline \multirow[t]{2}{*}{ Variable } & \multirow{2}{*}{$\begin{array}{l}\text { Posts, } \\
\mathrm{n}\end{array}$} & \multicolumn{7}{|l|}{ Overall reach } \\
\hline & & $\begin{array}{l}\text { Reach per post, } \\
\text { median }\end{array}$ & $\mathrm{IRR}^{\mathrm{a}}$ & $95 \% \mathrm{CI}$ & $P$ value $^{\mathrm{b}}$ & Adjusted IRR $^{\mathrm{c}}$ & $95 \% \mathrm{CI}$ & $P$ value $^{\mathrm{b}}$ \\
\hline Total & 92 & 248 & $\mathrm{~N} / \mathrm{A}^{\mathrm{d}}$ & N/A & N/A & N/A & N/A & N/A \\
\hline Health service & & & & & $<.001$ & & & $<.001$ \\
\hline 1 & 33 & 177 & 1 & N/A & & 1 & N/A & \\
\hline 2 & 25 & 114 & 0.94 & $0.56-1.59$ & & 1.11 & $0.61-2.04$ & \\
\hline 3 & 34 & 1432 & 5.20 & $3.22-8.39$ & & 6.18 & $3.33-11.47$ & \\
\hline First Nations (Australia) content & & & & & .11 & & & .20 \\
\hline No & 20 & 448 & 1 & N/A & & 1 & N/A & \\
\hline Yes, not local & 14 & 189 & 0.40 & $0.17-0.91$ & & 0.94 & $0.46-1.96$ & \\
\hline Yes, local & 58 & 248 & 0.69 & $0.37-1.28$ & & 0.61 & $0.33-1.11$ & \\
\hline Content source & & & & & .008 & & & .04 \\
\hline Original content & 67 & 192 & 1 & N/A & & 1 & N/A & \\
\hline Other sources & 25 & 1014 & 2.10 & $1.21-3.60$ & & 1.92 & $1.03-3.59$ & \\
\hline Video & & & & & .02 & & & .72 \\
\hline No & 70 & 244 & 1 & N/A & & 1 & N/A & \\
\hline Yes & 22 & 762 & 1.95 & $1.10-3.46$ & & 0.90 & $0.49-1.64$ & \\
\hline Other organizations tagged & & & & & .25 & & & .34 \\
\hline No & 83 & 247 & 1 & N/A & & 1 & N/A & \\
\hline Yes & 9 & 488 & 1.63 & $0.71-3.78$ & & 1.48 & $0.66-3.33$ & \\
\hline Hashtagged & & & & & .33 & & & .39 \\
\hline No & 14 & 312 & 1 & N/A & & 1 & N/A & \\
\hline Yes & 78 & 248 & 1.42 & $0.71-2.84$ & & 1.37 & $0.67-2.80$ & \\
\hline Tone of content & & & & & .19 & & & .02 \\
\hline $\begin{array}{l}\text { Neutral or disagreement between } \\
\text { coders }^{\mathrm{e}}\end{array}$ & 48 & 244 & 1 & N/A & & 1 & N/A & \\
\hline Positive & 44 & 294 & 1.39 & $0.85-2.29$ & & 0.51 & $0.29-0.90$ & \\
\hline
\end{tabular}

${ }^{\mathrm{a}}$ IRR: incident rate ratio.

${ }^{\mathrm{b}} P$ value calculated for whole variable using chi-square test.

${ }^{\mathrm{c}}$ Adjusted IRR for all other variables describing types of posts using multiple negative binomial regression.

${ }^{\mathrm{d}} \mathrm{N} / \mathrm{A}$ : not applicable.

${ }^{\mathrm{e}}$ Includes posts where all coded as neutral content and posts where coders could not agree on them being positive, neutral, or negative. No posts were coded as negative in tone or content by all coders.

Most posts $(58 / 92,63 \%)$ featured local First Nations content (rather than either no Australian First Nations content or content that was not local) and original content created by the health service $(67 / 92,73 \%$ posts; rather than content from other sources). There were no posts that featured content that was perceived as negative by all coders, such as intended negative emotional arousal featured in fear appeal TV campaigns; there was disagreement between coders on 37 posts, and the remainder were coded by all coders as either positive ( 44 posts) or neutral (11 posts). As noted in Textbox 1, neutral and posts with coder disagreement were treated as 1 category. Only 22 of 92 posts (24\%) included videos, and although most (78/92, 85\%) included hashtags, fewer than $10 \%$ tagged other organizations. One service paid to boost reach for 2 posts; all other posts (90/92, 97\%) were organic (nonpaid page posts).

The median overall reach of each post was 248 unique users. Posts reached more people if they were from health service 3, which had an established Facebook page preproject, if the featured content was from other sources (rather than original content created by the health service) or if the posts contained videos. Although there was no association with reach in the bivariate analysis, once adjusted for other post features, having positive content was associated with less reach (compared with neutral or contested content). In relation to the service that 
boosted the reach of 2 posts, we conducted a sensitivity analysis of our results by removing the 2 paid posts; the same variables had significant associations in all tables.
The 92 posts were shared 352 times (median 1 share per post; IQR 0-4; range 0-45; Table 2). Posts from health services 2 and 3 were shared more than those from health service 1 . Other characteristics were not associated with the sharing of posts (Multimedia Appendix 1).

Table 2. Total shares of each type of post, with and without controlling for reach.

\begin{tabular}{|c|c|c|c|c|c|c|c|c|}
\hline Variable & $\begin{array}{l}\text { Shares, } \\
\mathrm{n}\end{array}$ & $\begin{array}{l}\text { Shares, Medi- } \\
\text { an }\end{array}$ & $\mathrm{IRR}^{\mathrm{a}}$ & $95 \% \mathrm{CI}$ & $P$ value $^{\mathrm{b}}$ & $\begin{array}{l}\text { IRR (controlling } \\
\text { for reach) }\end{array}$ & $95 \% \mathrm{CI}$ & $P$ value ${ }^{\mathrm{b}}$ \\
\hline Total & 352 & 1 & $\mathrm{~N} / \mathrm{A}^{\mathrm{d}}$ & N/A & N/A & N/A & N/A & N/A \\
\hline Health service & & & & & $<.001$ & & & .005 \\
\hline 1 & 41 & 0 & 1 & N/A & & 1 & N/A & \\
\hline 2 & 61 & 1 & 1.96 & $0.85-4.56$ & & 2.90 & $1.43-5.88$ & \\
\hline 3 & 250 & 6 & 5.92 & $\begin{array}{l}2.76- \\
12.67\end{array}$ & & 2.77 & $1.47-5.21$ & \\
\hline First Nations (Australia) content & & & & & .22 & & & .45 \\
\hline No & 127 & 2 & 1 & N/A & & 1 & N/A & \\
\hline Yes, not local & 48 & 0 & 0.54 & $0.17-1.74$ & & 0.80 & $0.33-1.94$ & \\
\hline Yes, local & 177 & 1 & 0.48 & $0.20-1.14$ & & 0.66 & $0.34-1.27$ & \\
\hline Content source & & & & & .37 & & & .95 \\
\hline Original content & 229 & 1 & 1 & N/A & & 1 & N/A & \\
\hline Other sources & 123 & 4 & 1.44 & $0.65-3.20$ & & 1.02 & $0.56-1.88$ & \\
\hline Video & & & & & .20 & & & .23 \\
\hline No & 229 & 1 & 1 & N/A & & 1 & N/A & \\
\hline Yes & 123 & 4 & 1.71 & $0.75-3.90$ & & 1.47 & $0.78-2.75$ & \\
\hline Other organizations tagged & & & & & .82 & & & .87 \\
\hline No & 313 & 1 & 1 & N/A & & 1 & N/A & \\
\hline Yes & 39 & 4 & 1.15 & $0.34-3.83$ & & 1.08 & $0.44-2.65$ & \\
\hline Hashtagged & & & & & .26 & & & .58 \\
\hline No & 32 & 1 & 1 & N/A & & 1 & N/A & \\
\hline Yes & 320 & 1 & 1.79 & $0.65-4.96$ & & 1.25 & $0.56-2.78$ & \\
\hline Tone of content & & & & & .12 & & & .37 \\
\hline $\begin{array}{l}\text { Neutral or disagreement between } \\
\text { coders }\end{array}$ & 135 & 1 & 1 & N/A & & 1 & N/A & \\
\hline Positive & 217 & 1 & 1.75 & $0.86-3.56$ & & 1.29 & $0.74-2.24$ & \\
\hline
\end{tabular}

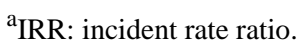

${ }^{\mathrm{b}} P$ values calculated for whole variables using chi-square test. We controlled for reach by offsetting the negative binomial regression model by the reach of the original posts.

${ }^{\mathrm{c}}$ We controlled for reach by offsetting the negative binomial regression model by the reach of the original posts.

${ }^{\mathrm{d}} \mathrm{N} / \mathrm{A}$ : not applicable.

There were 1099 reactions to the original posts (median 7 reactions per post; IQR 3-13; range 0-94; Table 3). In the bivariate analyses, posts from health service 3 (compared with health service 1) with content from other sources (rather than original content created by the health service) featuring video and with other organizations tagged attracted more reactions (likes or comments). After controlling for the reach of the posts, however, the differences between health services became insignificant, and posts with local Australian First Nations content attracted more reactions per person reached (compared with posts with no Australian First Nations content).

After adjusting for all variables, posts with content from other sources (compared with posts with original content) attracted significantly more reactions (IRR $1.57,95 \%$ CI 1.08-2.27; $P=.02$; Multimedia Appendix 2).

There were 990 reactions to the shared posts (median zero reactions per shared post; IQR 0-10; range 0-97; Table 4). 
Table 3. Reactions to each type of original post, before and after controlling for reach.

\begin{tabular}{|c|c|c|c|c|c|c|c|c|}
\hline Variable & Reactions, $\mathrm{n}$ & $\begin{array}{l}\text { Reactions, } \\
\text { Median }\end{array}$ & $\mathrm{IRR}^{\mathrm{a}}$ & $95 \% \mathrm{CI}$ & $P$ value ${ }^{\mathrm{b}}$ & $\begin{array}{l}\text { IRR (controlling for } \\
\text { reach) }\end{array}$ & $95 \% \mathrm{CI}$ & $P$ value $^{\mathrm{b}}$ \\
\hline Total & 1099 & 7 & $\mathrm{~N} / \mathrm{A}^{\mathrm{d}}$ & N/A & N/A & N/A & N/A & N/A \\
\hline Health service & & & & & $<.001$ & & & .25 \\
\hline 1 & 334 & 4 & 1 & N/A & & 1 & N/A & \\
\hline 2 & 162 & 5 & 0.64 & $0.38-1.08$ & & 1.30 & $0.88-1.94$ & \\
\hline 3 & 603 & 10 & 1.75 & $1.09-2.81$ & & 0.95 & $0.67-1.35$ & \\
\hline First Nations (Australia) content & & & & & .03 & & & .003 \\
\hline No & 182 & 9 & 1 & N/A & & 1 & N/A & \\
\hline Yes, not local & 92 & 5 & 0.72 & $0.35-1.48$ & & 0.96 & $0.59-1.58$ & \\
\hline Yes, local & 825 & 6 & 1.56 & $0.93-2.64$ & & 1.71 & $1.19-2.46$ & \\
\hline Content source & & & & & $<.001$ & & & $<.001$ \\
\hline Original content & 517 & 4 & 1 & N/A & & 1 & N/A & \\
\hline Other sources & 582 & 19 & 3.02 & $1.98-4.60$ & & 1.89 & $1.40-2.56$ & \\
\hline Video & & & & & .002 & & & .002 \\
\hline No & 661 & 6 & 1 & N/A & & 1 & N/A & \\
\hline Yes & 438 & 11 & 2.11 & $1.31-3.40$ & & 1.68 & $1.21-2.34$ & \\
\hline Other organizations tagged & & & & & .03 & & & .02 \\
\hline No & 890 & 6 & 1 & N/A & & 1 & N/A & \\
\hline Yes & 209 & 19 & 2.17 & $1.08-4.34$ & & 1.74 & $1.09-2.78$ & \\
\hline Hashtagged & & & & & .83 & & & .31 \\
\hline No & 158 & 7 & 1 & N/A & & 1 & N/A & \\
\hline Yes & 941 & 8 & 1.07 & $0.59-1.95$ & & 0.80 & $0.53-1.23$ & \\
\hline Tone of content & & & & & .97 & & & .25 \\
\hline $\begin{array}{l}\text { Neutral or disagreement between } \\
\text { coders }\end{array}$ & 571 & 6 & 1 & N/A & & 1 & N/A & \\
\hline Positive & 528 & 8 & 1.01 & $0.65-1.55$ & & 0.84 & $0.62-1.13$ & \\
\hline
\end{tabular}

${ }^{\mathrm{a}}$ IRR: incident rate ratio.

${ }^{\mathrm{b}} P$ values calculated for whole variables using the chi-square test. We controlled for reach by offsetting the negative binomial regression model by the reach of the original posts.

${ }^{\mathrm{c}} \mathrm{We}$ controlled for reach by offsetting the negative binomial regression model by the reach of the original posts.

${ }^{\mathrm{d}} \mathrm{N} / \mathrm{A}$ : not applicable. 
Table 4. Reactions to shared posts from each type of original post, before and after controlling for reach of shared posts.

\begin{tabular}{|c|c|c|c|c|c|c|c|c|}
\hline Variable & Reactions, $\mathrm{n}$ & $\begin{array}{l}\text { Reactions, } \\
\text { median }\end{array}$ & $\mathrm{IRR}^{\mathrm{a}}$ & $95 \% \mathrm{CI}$ & $P$ value ${ }^{\mathrm{b}}$ & $\begin{array}{l}\text { IRR (controlling for } \\
\text { reach) }\end{array}$ & $95 \% \mathrm{CI}$ & $P$ value $^{\mathrm{b}}$ \\
\hline Total & 990 & 0 & $\mathrm{~N} / \mathrm{A}^{\mathrm{d}}$ & N/A & N/A & N/A & N/A & N/A \\
\hline Health service & & & & & .003 & & & .02 \\
\hline 1 & 74 & 0 & 1 & N/A & & 1 & N/A & \\
\hline 2 & 215 & 0 & 3.84 & $\begin{array}{l}1.13- \\
13.02\end{array}$ & & 1.99 & $0.99-3.98$ & \\
\hline 3 & 701 & 10 & 9.19 & $\begin{array}{l}2.98- \\
28.33\end{array}$ & & 0.87 & $0.47-1.61$ & \\
\hline First Nations (Australia) content & & & & & .78 & & & .29 \\
\hline No & 231 & 1 & 1 & N/A & & 1 & N/A & \\
\hline Yes-not local & 92 & 0 & 0.57 & $0.10-3.25$ & & 1.54 & $0.62-3.84$ & \\
\hline Yes-local & 667 & 0 & 1.00 & $0.27-3.62$ & & 1.69 & $0.90-3.18$ & \\
\hline Content source & & & & & .02 & & & .003 \\
\hline Original content & 399 & 0 & 1 & N/A & & 1 & N/A & \\
\hline Other sources & 591 & 10 & 3.97 & $\begin{array}{l}1.31- \\
12.05\end{array}$ & & 2.17 & $1.31-3.61$ & \\
\hline Video & & & & & .21 & & & .57 \\
\hline No & 589 & 0 & 1 & N/A & & 1 & N/A & \\
\hline Yes & 401 & 8 & 2.17 & $0.65-7.22$ & & 1.18 & $0.67-2.10$ & \\
\hline Other organizations tagged & & & & & .29 & & & .11 \\
\hline No & 777 & 0 & 1 & N/A & & 1 & N/A & \\
\hline Yes & 213 & 34 & 2.53 & $\begin{array}{l}0.45- \\
14.27\end{array}$ & & 1.86 & $0.87-3.95$ & \\
\hline Hashtagged & & & & & .58 & & & .002 \\
\hline No & 211 & 1 & 1 & N/A & & 1 & N/A & \\
\hline Yes & 779 & 0 & 0.66 & $0.16-2.81$ & & 0.36 & $0.19-0.68$ & \\
\hline Tone of content & & & & & .52 & & & .27 \\
\hline $\begin{array}{l}\text { Neutral or disagreement between } \\
\text { coders }\end{array}$ & 433 & 0 & 1 & N/A & & 1 & N/A & \\
\hline Positive & 557 & 1 & 1.40 & $0.50-3.98$ & & 0.75 & $0.44-1.26$ & \\
\hline
\end{tabular}

aRR: incident rate ratio.

${ }^{\mathrm{b}} P$ values calculated for whole variables using the chi-square test. We controlled for reach by offsetting the negative binomial regression model by the reach of the shared posts.

${ }^{\mathrm{c}}$ We controlled for reach by offsetting the negative binomial regression model by the reach of the original posts.

${ }^{\mathrm{d}} \mathrm{N} / \mathrm{A}$ : not applicable.

Shared posts from original posts with content from nonlocal sources (rather than original content created by the health service) attracted more reactions, which persisted after controlling for reach and other post characteristics (IRR 1.57, 95\% CI 1.08-2.27; $P=.02$; Multimedia Appendix 3). Shared posts from health services 2 and 3 (compared with health service 1) had more reactions, but the magnitude of this association decreased after adjusting for reach and became nonsignificant once other characteristics were included in the model (Multimedia Appendix 3).

\section{Discussion}

We found that reach and sharing of posts was largely associated with the health service posting the content. This is unsurprising, given that only 1 service had an established Facebook presence before the study started. Otherwise, we found mixed evidence about other factors, including the use of First Nations-specific content, positive emotional content, video, tagging, and use of hashtags.

A counter-intuitive finding was that reactions to both original and shared posts were associated with content from other sources, not original content. A potential explanation for this 
could be the lower production quality of locally generated content. However, in this study, many of the posts with locally produced content were of high production quality, including being designed to be of appropriate length and tone for use on social media. Much of the locally generated content was developed and produced with the assistance of a former journalist and author VK, who has extensive professional experience in this area. Given that production quality is unlikely to be an issue, the results could be explained by 2 main factors: novelty and relevance.

Content from other sources may have had a higher novelty value than the local content; other research has shown that novelty can be an important factor in generating engagement [49]. This result may also reflect an effort to be particularly selective about choosing content from other sources, particularly when it contained nonlocal content, which is perceived to be specifically relevant to the local community. Our previous research $[15,50]$ and research by others [44] has found that sharing posts with content obtained from other sources but with a personalized message and posted by a close and trusted family member or friend can be perceived as localized, particularly if the content is highly resonant for the local context (for example, a post that conveys a commonly encountered scenario). Together, these factors may explain why content from other sources generated greater engagement. Further research is required to determine which of these factors explains our results and whether content creators can leverage them to boost engagement with their content.

The more mixed results for First Nations-specific content, both local and nonlocal, may be due to less selectivity being applied when choosing which content to post. It is also possible that, despite local branding and language, and high production values, the generic nature of the Australian government posts had a lower novelty value than other posts. It may also have been perceived as government content, which we have previously found is less trusted than content that is genuinely local [15].

Another unexpected finding was that positive content was associated with lower reach than posts that were coded as neutral and/or contested. Australia's First Nations people have called for change from deficit discourse to strengths-based messages and research approaches [51]. In our previous research, participants selected positive content for sharing, and the importance of contributing to a supportive environment was highlighted $[15,34,50]$. However, those studies explored decision making for sharing posts on personal pages, which may differ from the perceptions of posts by organizations. An evaluation of an Australian state government health promotion campaign's Facebook page found that users expressed a preference for positive content [49], but such content was not associated with higher engagement [30]. The lower reach achieved by positive content in our study may reflect the fact that the coding of most of the remaining posts was contested between the 2 coders or was coded as neutral because it included both positive and negative elements. It may be that unambiguously positive posts were perceived as less interesting or noteworthy than the posts with more ambiguous emotional content. Neutral and contested posts may have contained elements more likely to challenge and stimulate interpersonal discussion. This is important, as interpersonal communication stimulated by exposure to mass media antismoking campaigns is a factor in quitting intentions and behavior [52,53]. In previous research, we have also found evidence that this occurs in response to Facebook posts from friends and family about smoking [15]. We would not recommend avoiding posts with a positive tone based on these new data. Given that people tend to state a preference for positive content, it is likely that this is important for generating a positive connection to a page and receptiveness to messages posted. Therefore, positive content is likely to be complementary to a negative tone or mixed posts that may generate greater engagement.

Although our results were inconclusive, we were able to identify some areas for further research. First, as only 2 posts in our study received paid boosts, we did not perform a separate analysis of these factors. Previous research has found that the use of paid posts can significantly boost reach; however, it has also shown that organic (nonpaid) reach is associated with generating greater page engagement per person reached [30], suggesting that high quality, relevant, and appealing content is still essential if a Facebook campaign is to be successful. Other research has found that page administrators can leverage contextual factors that promote user engagement with pages (eg, the perceived trustworthiness of page, user patterns of use), but these factors cannot be controlled by page administrators [49]. Given the unique role of ACCHOs in delivering health services to First Nations Australians [54,55], posts by ACCHOs may generate engagement because they are seen as a worthy initiative.

The strengths of this study include that the content posted was selected and posted by the partner ACCHOs, based on what they perceived as relevant for their communities. Posting was integrated into routine work, ensuring that the approach was pragmatic and sustainable beyond this study. There were also a number of notable limitations. These included the fact that we did not perform separate analyses for different types of reactions, such as likes and comments, due to the small number of posts and that we were unable to extend our analysis beyond metrics of lower-level engagement, according to a spectrum of engagement outcomes as has been performed in other research [26]. Furthermore, we examined only postlevel data, not the impact of posts on page-level data. In addition, the sparsely populated geographical area, sample size (number of posts), and short duration limit the generalizability of our results. Finally, data from end users, which could have provided insights into the types of content that would be most likely to generate engagement, are not included in this paper.

\section{Conclusions}

Overall, we did not find a definitive set of characteristics that were clearly associated with reach and engagement. The exception was that content from other sources was associated with higher engagement than original content, which was an unexpected finding. However, it is important to note that our results do not suggest that community-based, localized content should be avoided. Similarly, although posts perceived by community members to have a positive tone generated less engagement, we do not suggest that these should be avoided. 
Rather, positive tone posts could be complementary to posts with characteristics that are likely to generate greater interaction. One of the key appeals of social media, specifically Facebook, is its ability to reach relatively small populations and to tailor content accordingly. For Australia's First Nations people, it can help with building social capital and connection. This study contributes to an understanding of the role of localized, community-based social media efforts and how these can be implemented. However, additional research is needed to understand the extent to which social media content can influence behavior.

\section{Acknowledgments}

The authors would like to thank the project partners Danila Dilba Health Service, Miwatj Health Aboriginal Corporation, Central Australian Aboriginal Congress (Congress), Aboriginal Medical Services Alliance Northern Territory (AMSANT), and all project participants.

This study was funded by the National Health and Medical Research Council, Australia, project grant number 1098308. MH is supported by a National Heart Foundation Australia Postdoctoral Fellowship award number 101938. BF is supported by a National Health and Medical Research Council early career fellowship APP1089403. The funding bodies had no role in the design of the study, data collection, analysis, and interpretation, or in writing the manuscript.

\section{Conflicts of Interest}

None declared.

\section{Multimedia Appendix 1}

Total shares of post controlling for reach, before and after adjusting for all other variables. [DOCX File, 25 KB-Multimedia Appendix 1]

\section{Multimedia Appendix 2}

Total reactions to original posts controlling for reach, before and after adjusting for all other variables. [DOCX File, 16 KB-Multimedia Appendix 2]

\section{Multimedia Appendix 3}

Total reactions to shared posts controlling for reach, before and after adjusting for all other variables. [DOCX File, 17 KB-Multimedia Appendix 3]

\section{References}

1. Abroms LC. Public health in the era of social media. Am J Public Health 2019 Feb;109(S2):S130-S131. [doi: 10.2105/ajph.2018.304947]

2. Kickbusch I. Health promotion 4.0. Health Promot Int 2019 Apr 1;34(2):179-181. [doi: 10.1093/heapro/daz022] [Medline: 30939200]

3. Jane M, Hagger M, Foster J, Ho S, Pal S. Social media for health promotion and weight management: a critical debate. BMC Public Health 2018 Jul 28;18(1):932 [FREE Full text] [doi: 10.1186/s12889-018-5837-3] [Medline: 30055592]

4. Partridge SR, Gallagher P, Freeman B, Gallagher R. Facebook groups for the management of chronic diseases. J Med Internet Res 2018 Jan 17;20(1):e21 [FREE Full text] [doi: 10.2196/jmir.7558] [Medline: 29343460]

5. Hunter RF, de la Haye K, Murray JM, Badham J, Valente TW, Clarke M, et al. Social network interventions for health behaviours and outcomes: a systematic review and meta-analysis. PLoS Med 2019 Sep;16(9):e1002890 [FREE Full text] [doi: 10.1371/journal.pmed.1002890] [Medline: 31479454]

6. Laranjo L, Arguel A, Neves AL, Gallagher AM, Kaplan R, Mortimer N, et al. The influence of social networking sites on health behavior change: a systematic review and meta-analysis. J Am Med Inform Assoc 2015 Jan;22(1):243-256 [FREE Full text] [doi: 10.1136/amiajnl-2014-002841] [Medline: 25005606]

7. Johns D, Langley TS, Lewis S. Use of social media for the delivery of health promotion on smoking, nutrition, and physical activity: a systematic review. Lancet 2017 Nov;390:S49. [doi: 10.1016/s0140-6736(17)32984-7]

8. Giustini D, Ali SM, Fraser M, Kamel Boulos MN. Effective uses of social media in public health and medicine: a systematic review of systematic reviews. Online J Public Health Inform 2018;10(2):e215 [FREE Full text] [doi: 10.5210/ojphi.v10i2.8270] [Medline: $\underline{30349633}$ ]

9. Kampmeijer R, Pavlova M, Tambor M, Golinowska S, Groot W. The use of e-health and m-health tools in health promotion and primary prevention among older adults: a systematic literature review. BMC Health Serv Res 2016 Sep 5;16(Suppl 5):290 [FREE Full text] [doi: 10.1186/s12913-016-1522-3] [Medline: 27608677] 
10. Welch V, Petkovic J, Pardo Pardo J, Rader T, Tugwell P. Interactive social media interventions to promote health equity: an overview of reviews. Health Promot Chronic Dis Prev Can 2016 Apr;36(4):63-75 [FREE Full text] [doi: 10.24095/hpcdp.36.4.01] [Medline: 27077792]

11. Moorhead A, Hazlett DE, Harrison L, Carroll JK, Irwin A, Hoving C. A new dimension of health care: systematic review of the uses, benefits, and limitations of social media for health communication. J Med Internet Res 2013 Apr 23;15(4):e85 [FREE Full text] [doi: 10.2196/jmir.1933] [Medline: 23615206]

12. Zhao Y, Zhang J. Consumer health information seeking in social media: a literature review. Health Info Libr J 2017 Dec;34(4):268-283 [FREE Full text] [doi: 10.1111/hir.12192] [Medline: 29045011]

13. Yu RP, Ellison NB, Lampe C. Facebook use and its role in shaping access to social benefits among older adults. J Broadcast Elect Media 2018 Jan 30;62(1):71-90. [doi: 10.1080/08838151.2017.1402905]

14. Sinclair TJ, Grieve R. Facebook as a source of social connectedness in older adults. Comput Hum Behav 2017 Jan;66:363-369. [doi: 10.1016/j.chb.2016.10.003]

15. Kerrigan V, Herdman RM, Thomas DP, Hefler M. 'I still remember your post about buying smokes': a case study of a remote Aboriginal community-controlled health service using Facebook for tobacco control. Aust J Prim Health 2019;25(5):443. [doi: 10.1071/py19008]

16. Kuipers M, Beard E, West R, Brown J. Associations between tobacco control mass media campaign expenditure and smoking prevalence and quitting in England: a time series analysis. Tob Control 2018 Jul;27(4):455-462 [FREE Full text] [doi: 10.1136/tobaccocontrol-2017-053662] [Medline: 28667091]

17. Durkin S, Brennan EB, Wakefield M. Mass media campaigns to promote smoking cessation among adults: an integrative review. Tob Control 2012 Mar;21(2):127-138. [doi: 10.1136/tobaccocontrol-2011-050345] [Medline: 22345235]

18. Brown J, Kotz D, Michie S, Stapleton J, Walmsley M, West R. How effective and cost-effective was the national mass media smoking cessation campaign 'Stoptober'? Drug Alcohol Depend 2014 Feb 1;135:52-58 [FREE Full text] [doi: 10.1016/j.drugalcdep.2013.11.003] [Medline: 24322004]

19. Xu X, Alexander RL, Simpson SA, Goates S, Nonnemaker JM, Davis KC, et al. A cost-effectiveness analysis of the first federally funded antismoking campaign. Am J Prev Med 2015 Mar;48(3):318-325 [FREE Full text] [doi: 10.1016/j.amepre.2014.10.011] [Medline: 25498550]

20. Allom V, Jongenelis M, Slevin T, Keightley S, Phillips F, Beasley S, et al. Comparing the cost-effectiveness of campaigns delivered various combinations of television and online media. Front Public Health 2018;6:83 [FREE Full text] [doi: 10.3389/fpubh.2018.00083] [Medline: 29629366]

21. Baskerville NB, Azagba S, Norman C, McKeown K, Brown KS. Effect of a digital social media campaign on young adult smoking cessation. Nicotine Tob Res 2016 Mar;18(3):351-360. [doi: 10.1093/ntr/ntv119] [Medline: 26045252]

22. Bold KW, Hanrahan TH, O'Malley SS, Fucito LM. Exploring the utility of web-based social media advertising to recruit adult heavy-drinking smokers for treatment. J Med Internet Res 2016 May 18;18(5):e107 [FREE Full text] [doi: 10.2196/jmir.5360] [Medline: 27194456]

23. Most Popular Social Networks Worldwide as of July 2019, Ranked by Number of Active Users (in Millions). Statista. 2019. URL: https://www.statista.com/statistics/272014/global-social-networks-ranked-by-number-of-users/ [accessed 2019-11-05]

24. Cowling D. Social Media Statistics Australia. Social Media News. 2019. URL: https://www.socialmedianews.com.au/ social-media-statistics-australia-july-2019/ [accessed 2019-09-13]

25. Kordzadeh ND, Young DK. Exploring hospitals' use of Facebook: thematic analysis. J Med Internet Res 2018 May 16;20(5):e190 [FREE Full text] [doi: 10.2196/jmir.9549] [Medline: 29769173]

26. Platt T, Platt J, Thiel DB, Kardia SL. Facebook advertising across an engagement spectrum: a case example for public health communication. JMIR Public Health Surveill 2016 May 30;2(1):e27 [FREE Full text] [doi: 10.2196/publichealth.5623] [Medline: 27244774]

27. Chopik WJ. The benefits of social technology use among older adults are mediated by reduced loneliness. Cyberpsychol Behav Soc Netw 2016 Sep;19(9):551-556 [FREE Full text] [doi: 10.1089/cyber.2016.0151] [Medline: 27541746]

28. Kite J, Foley BC, Grunseit AC, Freeman B. Please like me: Facebook and public health communication. PLoS One 2016;11(9):e0162765 [FREE Full text] [doi: 10.1371/journal.pone.0162765] [Medline: 27632172]

29. Theiss S, Burke RM, Cory JL, Fairley TL. Getting beyond impressions: an evaluation of engagement with breast cancer-related Facebook content. Mhealth 2016 Nov;2:- [FREE Full text] [doi: 10.21037/mhealth.2016.10.02] [Medline: 27840816]

30. Kite J, Grunseit A, Li V, Vineburg J, Berton N, Bauman A, et al. Generating engagement on the make healthy normal campaign Facebook page: analysis of Facebook analytics. JMIR Public Health Surveill 2019 Jan 14;5(1):e11132 [FREE Full text] [doi: 10.2196/11132] [Medline: 31344679]

31. Barnhart B. How the Facebook Algorithm Works and Ways to Outsmart It. Sprout Social. 2019. URL: https://sproutsocial. com/insights/facebook-algorithm/ [accessed 2019-09-13]

32. Carlson B. For Aboriginal and Torres Strait Islander people what are the health impacts of social media?2016. Croakey. 2019. URL: https://croakey.org/for-aboriginal-and-torres-strait-islander-people-what-are-the-health-impacts-of-social-media/ [accessed 2019-09-13] 
33. Carlson B, Frazer R. Social Media Mob: Being Indigenous Online. Macquarie Park, NSW: Macquarie University; 2018.

34. Hefler M, Kerrigan V, Henryks J, Freeman B, Thomas DP. Social media and health information sharing among Australian Indigenous people. Health Promot Int 2019 Aug 1;34(4):706-715 [FREE Full text] [doi: 10.1093/heapro/day018] [Medline: 29672684]

35. Hefler M, Kerrigan V, Henryks J, Freeman B, Thomas DP. Social media and health information sharing among Australian Indigenous people. Health Promot Int 2019 Aug 1;34(4):706-715 [FREE Full text] [doi: 10.1093/heapro/day018] [Medline: 29672684]

36. Walker T, Palermo CK, Klassen K. Considering the impact of social media on contemporary improvement of Australian aboriginal health: scoping review. JMIR Public Health Surveill 2019 Feb 5;5(1):e11573 [FREE Full text] [doi: 10.2196/11573] [Medline: 30720442]

37. Rennie E, Yunkaporta T, Holcombe-James I. Privacy at the margins| privacy versus relatedness: managing device use in Australia's remote aboriginal communities. Int J Commun 2018 Mar;12:1291-1309 [FREE Full text]

38. Brusse C, Gardner K, McAullay D, Dowden M. Social media and mobile apps for health promotion in Australian Indigenous populations: scoping review. J Med Internet Res 2014 Dec 10;16(12):e280 [FREE Full text] [doi: 10.2196/jmir.3614] [Medline: 25498835]

39. Berends L, Halliday R. Capacity building and social marketing promotes healthy lifestyle behaviour in an Australian Aboriginal community. Aust J Rural Health 2018 Jul 16:-. [doi: 10.1111/ajr.12421] [Medline: 30011105]

40. Australian Aboriginal and Torres Strait Islander Health Survey: Updated Results, 2012-13. Australian Bureau of Statistics. Canberra; 2014. URL: https://www.abs.gov.au/ausstats/abs@.nsf/mf/4727.0.55.006 [accessed 2019-09-13]

41. Tackling Indigenous Smoking. Australian Government. 2019. URL: https://www.health.gov.au/initiatives-and-programs/ tackling-indigenous-smoking [accessed 2019-09-13]

42. 2016 Census Reveals the Changing Face of the Northern Territory. Australian Bureau of Statistics. 2017. URL: https:/ /www.abs.gov.au/AUSSTATS/abs@.nsf/mediareleasesbyReleaseDate/ C73D7CC81CA1FD2FCA258148000A4067? OpenDocument [accessed 2019-09-13]

43. National Health Survey: First Results, 2017-18. Australian Bureau of Statistics. 2019. URL: https://www.abs.gov.au/ statistics/health/health-conditions-and-risks/national-health-survey-first-results/latest-release [accessed 2019-09-13]

44. National Aboriginal and Torres Strait Islander Social Survey, 2014-15. Australian Bureau of Statistics. 2017. URL: https:/ /www.abs.gov.au/ausstats/abs@.nsf/mf/4714.0 [accessed 2019-09-13]

45. National Health and Medical Research Council. Ethical Conduct in Research With Aboriginal and Torres Strait Islander Peoples and Communities: Guidelines for Researchers and Stakeholders. Canberra, Australia: Commonwealth of Australia; 2018.

46. Updated: Lifespan of a Social Media Post. M to M. 2019. URL: https://mtomconsulting.com/ updated-lifespan-of-a-social-media-post/ [accessed 2019-10-15]

47. Freeman B, Kelly B, Baur L, Chapman K, Chapman S, Gill T, et al. Digital junk: food and beverage marketing on Facebook. Am J Public Health 2014 Dec;104(12):e56-e64. [doi: 10.2105/AJPH.2014.302167] [Medline: 25322294]

48. Hutchinson MK, Holtman MC. Analysis of count data using poisson regression. Res Nurs Health 2005 Oct;28(5):408-418. [doi: 10.1002/nur.20093] [Medline: 16163676]

49. Kite J, McGill B, Freeman B, Vineburg J, Li V, Berton N, et al. User perceptions of the campaign Facebook page: a mixed methods study. Soc Media Soc 2018 Aug 16;4(3):205630511879463. [doi: 10.1177/2056305118794639]

50. Hefler M, Kerrigan V, Freeman B, Boot GR, Thomas DP. Using Facebook to reduce smoking among Australian Aboriginal and Torres Strait Islander people: a participatory grounded action study. BMC Public Health 2019 May 21;19(1):615 [FREE Full text] [doi: 10.1186/s12889-019-6918-7] [Medline: $\underline{\text { 31113480] }}$

51. Fogarty W, Lovell M, Langenberg J, Heron MJ. Deficit Discourse and Strengths-based Approaches: Changing the Narrative of Aboriginal and Torres Strait Islander Health and Wellbeing. Melbourne: Lowitja Institute; 2018.

52. Jeong M, Tan AS, Brennan E, Gibson L, Hornik RC. Talking about quitting: interpersonal communication as a mediator of campaign effects on smokers' quit behaviors. J Health Commun 2015;20(10):1196-1205 [FREE Full text] [doi: 10.1080/10810730.2015.1018620] [Medline: 26147367]

53. Dunlop S, Cotter T, Perez D. When your smoking is not just about you: antismoking advertising, interpersonal pressure, and quitting outcomes. J Health Commun 2014;19(1):41-56. [doi: 10.1080/10810730.2013.798375] [Medline: 23967804]

54. Campbell M, Hunt J, Scrimgeour DJ, Davey M, Jones V. Contribution of aboriginal community-controlled health services to improving aboriginal health: an evidence review. Aust. Health Review 2018;42(2):218-226. [doi: 10.1071/ah16149]

55. Thompson SC, Haynes E, Shahid S, Woods JA, Teng TH, Davidson PM, et al. Shedding light or fanning flames?: a consideration of the challenges in exploring the relative effectiveness of Aboriginal Community Controlled Health Services. Qual Primary Care 2015;23(3):141-149.

\footnotetext{
Abbreviations

ACCHO: Aboriginal Community Controlled Health Service

IRR: incident rate ratio
} 


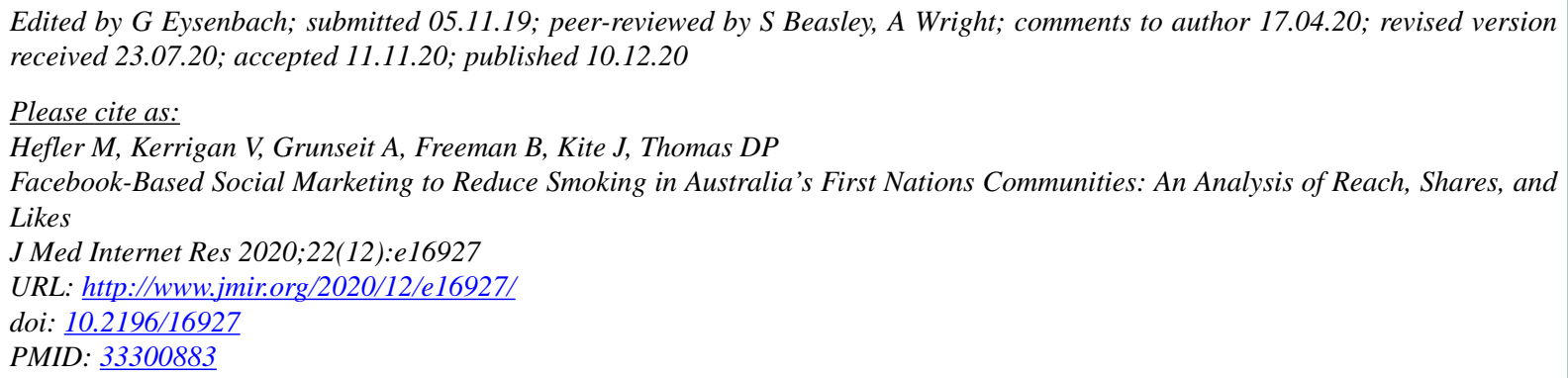

CMarita Hefler, Vicki Kerrigan, Anne Grunseit, Becky Freeman, James Kite, David P Thomas. Originally published in the Journal of Medical Internet Research (http://www.jmir.org), 10.12.2020. This is an open-access article distributed under the terms of the Creative Commons Attribution License (https://creativecommons.org/licenses/by/4.0/), which permits unrestricted use, distribution, and reproduction in any medium, provided the original work, first published in the Journal of Medical Internet Research, is properly cited. The complete bibliographic information, a link to the original publication on http://www.jmir.org/, as well as this copyright and license information must be included. 